\title{
AGE-RAGE Stress and Coronary Artery Disease
}

\author{
Kailash Prasad, BSc (Distinction), MBBS (Hons), MD, PhD, DSc, FRCPC, FACC, FIACS, FICA ${ }^{1}$ \\ ${ }^{1}$ Department of Physiology (APP), College of Medicine, University of \\ Saskatchewan, Saskatoon, Canada \\ Address for correspondence Kailash Prasad, MBBS (Hons), MD, PhD, \\ DSc, Department of Physiology (APP), College of Medicine, University \\ Int J Angiol 2021;30:4-14. \\ of Saskatoon, 107 Wiggins Road, Saskatoon, SK S7N 5E5, Canada \\ (e-mail: k.prasad@usask.ca).
}

Abstract
Keywords
- advanced glycation
end products (AGE)
- cell receptor for AGE
- soluble receptors AGE
- coronary artery
disease (CAD)
- atherosclerosis
- atherosclerotic
plaque rupture
- AGE-RAGE stress
- treatment modalities

for AGE-RAGE stress-
induced CAD

Coronary artery atherosclerosis and atherosclerotic plaque rupture cause coronary artery disease (CAD). Advanced glycation end products (AGE) and its cell receptor RAGE, and soluble receptor (SRAGE) and endogenous secretory RAGE (esRAGE) may be involved in the development of atherosclerosis. AGE and its interaction with RAGE are atherogenic, while sRAGE and esRAGE have antiatherogenic effects. AGE-RAGE stress is a ratio of AGE/sRAGE. A high AGE-RAGE stress results in development and progression of CAD and vice-versa. AGE levels in serum and skin, AGE/sRAGE in patients with CAD, and expression of RAGE in animal model of atherosclerosis were higher, while serum levels of esRAGE were lower in patients with CAD compared with controls. Serum levels of SRAGE in CAD patients were contradictory, increased or decreased. This contradictory data may be due to type of patients used, because the sRAGE levels are elevated in diabetics and end-stage renal disease. AGE/SRAGE ratio is elevated in patients with reduced or elevated levels of serum sRAGE. It is to stress that AGE, RAGE, SRAGE, or esRAGE individually cannot serve as universal biomarker. AGE and SRAGE should be measured simultaneously to assess the AGE-RAGE stress. The treatment of CAD should be targeted at reduction in AGE levels, prevention of AGE formation, degradation of AGE in vivo, suppression of RAGE expression, blockade of RAGE, elevation of sRAGE, and use of antioxidants. In conclusion, AGE-RAGE stress would initiate the development and progression of atherosclerosis. Treatment modalities would prevent, regress, and slow the progression of CAD.
Coronary artery disease (CAD), also known as coronary heart disease (CHD), and ischemic heart disease are due to reduced blood supply to the heart. Coronary artery stenosis manifests in clinical syndrome called stable angina and acute coronary syndrome (ACS). Acute coronary syndrome includes unstable angina and ACS (ST-segment elevated myocardial infarction [STEMI], and non-ST-segment elevated myocardial infarction [NSTEMI]). ${ }^{1}$ Although ACS, CHD, and CAD are used interchangeably, they are not the same. ACS is the subcategory of CAD, while CHD is the result of CAD. According to World Health Organization, CAD is the main cause of death globally (>9 million death in 2016). ${ }^{2}$ Russia, United States, Ukraine, Germany, and Brazil had the most number of death due to CAD in $2015 .^{3}$ They also reported that mortality has progres- sively decreased from 2005 to 2015 . Fifty percent of all death from cardiovascular disease (CVD) is due to CAD. ${ }^{4}$ CAD is due to atherosclerosis. As atherosclerosis progresses, atherosclerotic plaques rupture resulting in arterial occlusion or dislodged material from plaques blocking the smaller branches of coronary artery. The risk factors for atherosclerosis or CAD include dyslipidemia, ${ }^{5,6}$ diabetes, ${ }^{7}$ hypertension, ${ }^{8}$ cigarette smoking, ${ }^{9,10}$ obesity, ${ }^{10}$ hyperhomocysteinemia, ${ }^{11}$ and C-reactive protein. ${ }^{12}$ Advanced glycation end products (AGE) and its cell receptors RAGE (receptor for AGE), and soluble receptors sRAGE (soluble receptor for AGE) and esRAGE (endogenous secretory receptor for AGE) have been implicated in various diseases including, NSTEMI, ${ }^{13}$ restenosis following percutaneous coronary intervention (PCI), ${ }^{14}$ published online January 21, 2021 (c) 2021. International College of Angiology. All rights reserved. Thieme Medical Publishers, Inc., 333 Seventh Avenue, 18th Floor, New York, NY 10001, USA
DOI https://doi.org/ $10.1055 / \mathrm{s}-0040-1721813$. ISSN 1061-1711. 
carotid artery de-endothelialization-induced neointima expansion in wild-type mice, ${ }^{15,16}$ streptozotocin-induced diabetes accelerated atherosclerosis in apo-E-deficient mice, ${ }^{17}$ and accelerated atherosclerosis in apoE-deficient mice. ${ }^{18}$ This chapter addresses the RAGE stress and the role of AGE-RAGE stress in the pathogenesis of atherosclerosis, AGE, RAGE, and sRAGE levels in patients with CAD and the treatment strategy for prevention, regression, and slowing of the progression of CAD.

\section{AGE-RAGE Stress}

AGEs are heterogenous groups of irreversible adducts produced by nonenzymatic glycation and glycoxidation of proteins, nucleic acid with reducing sugars. ${ }^{19,20}$ There are four receptors for AGE: full length cell receptor for AGE (RAGE), N-truncated RAGE, and two C-truncated RAGE. Interaction of AGE with RAGE has adverse effects on cell function and initiates and accelerate the progression of various diseases. This will be discussed in detail in a section on atherogenic effects of AGE and its interaction with RAGE. $\mathrm{N}$-truncated RAGE is bound in the plasma membrane, but its function is not well understood as yet. C-truncated RAGE has two isoforms, cleaved RAGE (c-RAGE), and endogenous secretory RAGE (esRAGE). c-RAGE is proteolytically cleaved from full length RAGE, ${ }^{21}$ while esRAGE is produced from alternative mRNA splicing of full-length RAGE. ${ }^{22}$ c-RAGE and esRAGE lack cytosolic and transmembrane domain and circulate in the blood. sRAGE comprises of both c-RAGE and esRAGE. Twenty to thirty percent of SRAGE is esRAGE. $^{23,24}$ sRAGE binding with ligands does not activate intracellular signaling. Both sRAGE and esRAGE compete with RAGE for ligand binding and thus have protective effects against adverse effects of AGE-RAGE binding. Prasad and Mishra $^{25}$ have coined three terminologies in the AGE-RAGE axis that comprises of AGE, RAGE, and sRAGE. AGE and its interaction with RAGE have been coined as stressors because they produce adverse effects. The agents that reduce the adverse effects of AGE and its interaction with RAGE have been coined as antistressors that include endogenous, exogenous, and down regulation of RAGE expression. Endogenous antistressors include enzymatic degraders of AGE (glyoxalase-1, glyoxalase-2), AGE receptor-mediated degraders of AGE (AGE receptor-1 [AGER-1], AGER-2), and SRAGE. Exogenous antistressors include reduction in AGE consumption and exogenous administration of sRAGE. AGERAGE stress has been defined as a shift in balance between stressors and antistressors in favor of stressors. ${ }^{25}$ Prasad and Mishra $^{25}$ have constructed a formula to assess AGE-RAGE stress. The ratio of AGE/sRAGE has been proposed as a simple and feasible measure of AGE-RAGE stress in clinical practice. A high index of AGE-RAGE stress would initiate the development and progression of diseases including CAD.

\section{Atherogenic Effects of AGE-RAGE Stress}

AGE-RAGE stress could produce atherosclerosis in two ways: direct effect of AGE and interaction of AGE with RAGE.

\section{Direct Effects of AGE}

AGE modifies apoB100 that makes low-density lipoprotein (LDL) more atherogenoic. ${ }^{26}$ Glycation of apoB and phospholipid component of LDL alters the LDL clearance and increases the susceptibility of LDL oxidation. ${ }^{27,28}$ Glycated LDL decreases its recognition by LDL receptors, ${ }^{29}$ and increases smooth muscle cell proliferation and differentiation. ${ }^{30,31}$ AGE interferes with reverse cholesterol transport ${ }^{29}$ resulting in extracellular accumulation of cholesterol. AGE enhances accumulation of cholesterol and its esters in macrophages in vitro. ${ }^{32}$ AGE increases synthesis of extracellular matrix ${ }^{33}$ and cross-binds with collagen. ${ }^{34}$ Cross-linking of AGE with collagen and elastin enhances arterial stiffness. ${ }^{35}$ Matrix-bond AGE increases expression of endothelin- $1^{36}$ that has been suggested to be involved in the development of atherosclerosis. ${ }^{33}$ Generation of nitric oxide (NO) is reduced by $\mathrm{AGE}^{37}$ and oxidized LDL. ${ }^{38}$ AGE quenches $\mathrm{NO}^{39}$ and matrix-bond AGE quenches and inactivates NO. ${ }^{40}$ Matrix-bond AGE inhibits antiproliferative activity of NO. ${ }^{41}$ In summary, the above data suggest that AGE initiates and helps in progression of atherosclerosis through LDL oxidation, interfering reverse cholesterol transport, altering LDL clearance, increasing smooth muscle cell proliferation and differentiation, increasing expression of endothelin and extracellular matrix, reducing generation of $\mathrm{NO}$, and quenching and inactivation of NO.

\section{Effects of Interaction of AGE with RAGE}

AGE interacts with RAGE to produce reactive oxygen species $(\mathrm{ROS})^{42}$ that activates nuclear factor kappa-B (NF-kB) that in turn activates numerous proinflammatory genes of cytokines such as tumor necrosis factor- $\alpha$ (TNF- $\alpha$ ), interleukin (IL)-1, IL-2, IL-6, IL-8, IL-9. ${ }^{43,44}$ Interaction of AGE with RAGE increases expression of intercellular adhesion molecule-1 (ICAM-1), vascular cell adhesion molecule-1 (VCAM-1), and E-selectin. ${ }^{45}$ ROS itself upregulates the expression of ICAM-1, VCAM-1, and endothelial leucocytes adhesion molecules. $^{46-48}$ AGE increases expression of monocyte chemoattractant protein-1 (MCP-1) in mesangial cells, ${ }^{49}$ and MCP-1 and vascular endothelial growth factor in human-cultured mesangial cells. ${ }^{50}$ Expression and secretion of granulocyte macrophage-colony stimulating factor (GM-CSF) by macrophages is enhanced with AGE. ${ }^{51}$ AGE-RAGE interaction enhances expression of insulin-like growth factor-1 and platelet-derived growth factor (PDGF). ${ }^{52}$ AGE enhances the expression of transforming growth factor- $\beta{ }^{53}$ These data suggest that AGE-RAGE interaction enhances the expression of biomolecules required for initiation and progression of atherosclerosis. It also implies that sRAGE is protective against AGE-RAGE-induced atherosclerosis.

\section{Mechanisms Involved in AGE-RAGE Stress- Induced Atherosclerosis and Plaque Rupture}

AGE and its interaction with RAGE-induced atherogenic biomolecules have been implicated in atherosclerosis and have been described in detail by Prasad ${ }^{9}$ and Prasad and 
Bhanumathy. ${ }^{54}$ Most of the ACS is associated with plaque rupture. $^{55,56}$ Matrix metalloproteinases (MMPs) have been implicated in plaque rupture. There is overexpression of MMPs in atherosclerotic lesions. An increased expression of MMP1 in several cell types in human carotid atherosclerotic plaques and its correlation with histopathological evidence of plaque instability have been reported by Nikkari et al. ${ }^{57}$ MMP-9 has been reported to be elevated in atherectomy specimen from patients with unstable angina. ${ }^{58}$ IL-1, PDGF, and TNF- $\alpha$ have been shown to stimulate expression of MMPs. ${ }^{59-61}$ Oxidative stress increases the expression of MMP-1 and MMP-3. ${ }^{62,63}$ ROS may be involved in stability of atherosclerotic plaques. ${ }^{64}$ The above data also suggest that AGE and its interaction with RAGE may be involved in the instability and rupture of atherosclerotic plaque and ACS.

\section{Serum Levels of AGE, RAGE, SRAGE, esRAGE, and AGE-RAGE Stress in Patients with CAD}

If AGE-RAGE stress is involved in the pathophysiology of CAD, then the serum levels of AGE, RAGE, and AGE/sRAGE should be elevated while the levels of sRAGE and esRAGE would be reduced. The following section would deal with the serum levels of AGE, RAGE, sRAGE, esRAGE, and AGE/sRAGE in patients with CAD.

\section{Serum Levels of AGE in Patients with CAD}

Levels of AGEs have been measured in serum/plasma and skin autofluorescence in patients with CAD. Skin autofluorescence is a noninvasive measurement of levels of AGE in skin. ${ }^{65}$ Serum levels of AGE are elevated in CAD patients with type 2 diabetes as compared with CAD patients without diabetes. ${ }^{66}$ Kilhovd et al $^{67}$ measured the serum levels of AGEs in 1141 nondiabetic individuals at base line and followed up for 18 years. Eighty-four patients died of CAD during this follow-up period and the death was associated with elevated levels of serum AGE. The data suggest that serum levels of AGE can predict CHD mortality in nondiabetic women but not in nondiabetic men. Kanauchi et $\mathrm{al}^{68}$ measured serum levels of AGE in nondiabetic patients with significantly stenosed vessels assessed by coronary angiography, and found that serum levels of AGEs were significantly higher in nondiabetic subjects with CAD than in control subjects and were significantly correlated with number of significantly stenosed vessels. The levels of AGEs were significantly higher in group with three vessels disease than in group with zero and 1 vessel disease. McNair et al ${ }^{13}$ have reported that the serum levels of AGE were higher in NSTEMI subjects compared with control subjects. The also showed that the levels AGE were higher to similar extent in patients with 1 vessel, 2 vessels, and 3 vessels disease compared with control subjects. McNair et $\mathrm{al}^{14}$ reported that the serum levels of AGE pre-PCI were higher in patients of both groups who developed or did not develop post-PCI restenosis but the post-PCI levels of AGE were significantly higher in patients who developed post-PCI restenosis compared with control subjects. Serum AGE levels are elevated in patients undergoing PCI and is reported to be an independent risk factor for restenosis in diabetic patients. ${ }^{69}$ Serum levels of AGE were elevated in type 2 diabetic patients with obstructive CAD compared with diabetics with nonobstructive CAD and levels of AGE correlated with degree of coronary artery atherosclerosis. ${ }^{70}$ This association was independent of other risk factors for CAD including hypertension, cigarette smoking, hyperlipidemia, and hyperuricemia. Serum levels of AGE have been suggested to be a biomarker for severity of coronary artery atherosclerosis in type 2 diabetic patients independent of hypertension, hyperlipidemia, and cigarette smoking. ${ }^{71}$ Kerkeni et al $^{72}$ have reported that there was an association between elevated levels of pentosidine (a type of AGE) and obstructive CAD and its severity was independent of diabetes. Plasma levels of AGEs like carboxymethyl-lysine (CML), carboxyethyl-lysine (CEL), pentosidine, and tetrahydropyrimidine (THP) were elevated in diabetic patients. ${ }^{73}$ Higher levels of plasma pentosidine but not CML, CEL, and THP were associated with moderate-to-high coronary artery calcium score compared with a low coronary artery calcium score in type 1 diabetic patients. An association between higher CML and cardiovascular mortality has been reported in a prospective study of over 1,000 patients over 65 years of

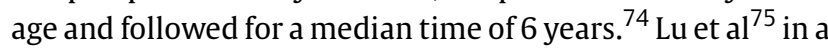
cross-section study showed that the serum levels of glycated albumin were significantly elevated in patients with both type 2 diabetes and significant CAD. They also reported that there was no significant difference in glycated albumin levels in nondiabetic patients with or without CAD. Glycated albumin levels were associated with angiographic CAD severity, extent and number of diseased coronary arteries in diabetic CAD patients. Serum levels of AGE were significantly elevated in diabetic patients with CHD as compared with those without $\mathrm{CHD}{ }^{76}$

In some studies, AGE levels were measured with skin autofluorescence and the results were similar to that measured with immunoassay in CAD patients. Mulder et $\mathrm{al}^{77}$ reported that skin autofluorescence is elevated in patients with stable CAD compared with healthy control. Yozgatli et al $^{78}$ have shown that there was a correlation between increased levels of skin autofluorescence and CAD independent of hemoglobin A1c levels in type 2 diabetic patients. Conway et $\mathrm{al}^{79}$ elevated skin autofluorescence was associated with severity of coronary artery calcium score in type 1 diabetics. There was no significant difference in skin autofluorescence among unstable angina, NSTEMI, and STEMI at admission. However, AGE levels increased significantly in patients with cardiac events during follow-up. ${ }^{80}$ It has been reported that increased levels of AGE in patients with diabetes accelerate the development and progression of heart failure both indirectly through coronary dysfunction and atherosclerosis, ${ }^{81}$ and directly through its action on myocardiam. ${ }^{82}$ In summary, the serum levels of AGE are elevated in patients with CAD.

\section{Serum Levels of sRAGE in CAD Patients}

There are conflicting reports about the use of sRAGE as a biomarker for CVD. Selvin et $\mathrm{al}^{83}$ measured the plasma levels 
of sRAGE in 1201 participants who had normal kidney function, and no history of CVD, and followed up for 18 years. They found that during that period 192 (16\%) participants developed CAD events that was associated with low levels of plasma sRAGE suggesting that low sRAGE levels were biomarker of future chronic CAD. Falcone et $\mathrm{al}^{84}$ measured the plasma levels of sRAGE in 328 nondiabetic patients with angiographically proven CAD and 328 age-matched healthy control and showed that low plasma levels of sRAGE were independently associated with CAD in nondiabetic individuals. It has been reported that plasma levels of sRAGE were significantly lower in patients with ACS (unstable angina and myocardial infarction) than in patients with stable angina. ${ }^{85}$ They also reported that the plasma levels of sRAGE were not affected by statin therapy, number of diseased vessels, and extent of coronary disease. Other investigators ${ }^{84-87}$ have also reported reduced plasma levels of sRAGE in patients with ACS and stable angina when compared with control subjects. It has been reported that plasma levels of SRAGE were significantly lower in patients with CAD with or without peripheral vascular disease (PVD) compared with control. ${ }^{88}$ They also showed that CAD patients with PVD had lower plasma sRAGE compared with those without PVD. Low levels of serum sRAGE in patients with suspected CAD were predictive of cardiovascular events after follow-up for 48 months. $^{89}$ Low levels of sRAGE have been reported to be associated with high coronary calcium score. ${ }^{90}$ Serum levels of sRAGE have been reported to be lower in NSTEMI patients compared with control subjects. ${ }^{13}$ Pre-PCI levels of serum SRAGE were significantly lower in NSTEMI patients who developed or not developed post-PCI restenosis compared with control subjects; however, the levels of sRAGE were significantly lower in patients who developed restenosis compared with those who did not develop restenosis. ${ }^{14}$ Pre- and post-PCI levels of sRAGE in NSTEMI patients were similar who did not develop restenosis following PCI. On the other hand, post-PCI levels of sRAGE were significantly lower than those who developed restenosis. ${ }^{14}$ McNair et al ${ }^{13}$ have shown that sRAGE levels were inversely associated with number of stenosed vessels. McNair et $\mathrm{al}^{91}$ also reported that levels of SRAGE were lower in NSTEMI patients compared with control and that there was a negative correlation between sRAGE and cardiac troponin-I (cTnI).

However, there are numerous papers showing increases in the serum levels of sRAGE in patients with CAD. It has been reported that plasma levels of sRAGE were higher in patients with NSTEMI-ACS than in patients with stable angina and positively correlated with cTnI. $^{92}$ Nakamura et al ${ }^{93}$ have shown that serum levels of sRAGE were significantly higher in diabetic patients with CAD than in diabetic patients without CAD. SRAGE levels are directly corelated with presence and severity of CAD in patients with and without diabetes. ${ }^{70,94-96}$ Wang et al $^{97}$ measured the plasma levels of SRAGE in patients with normal coronary artery, nonobstructive coronary artery $(<50 \%$ stenosed coronary artery), stable angina and ACS, and observed that plasma levels of sRAGE were higher compared with control group, nonobstructive coronary artery, and stable angina group. The levels did not change significantly in patients with stable angina and nonstenosed coronary artery compared with control subjects. They concluded that the elevated levels of SRAGE may be independently associated with severity of $\mathrm{CAD}$ and inflammation. It would have been useful to measure the plasma levels of AGE. It is possible that plasma levels of AGE are also elevated, and its elevation is greater than the elevation of sRAGE in these patients resulting in an increase in the ratio of AGE/SRAGE and hence adverse effects on coronary artery. They have measured $\mathrm{S} 100 \mathrm{~A}_{12}$ a ligand for SRAGE. However, they did not provide the ratio of $S 100_{12} /$ SRAGE. Increase in the ratio of AGE/sRAGE has been reported to be risk factor/biomarker for diseases. ${ }^{25,98}$ Park et al ${ }^{96}$ have reported that plaque vulnerability was associated with increased levels of plasma sRAGE and MMP-9 in patients with acute myocardial infarction compared with control subjects. sRAGE is a protective biochemical and hence its increased levels should not be responsible for plaque vulnerability. Also increased levels of sRAGE are known to decrease the levels MMPs. ${ }^{99,100}$ It is also possible that that AGE levels are elevated and the elevation is greater than sRAGE increasing the ratio of AGE/sRAGE that would increase the MMP levels. ${ }^{99}$ It is known that AGE-RAGE interaction increases the generation of MMP-9 that in turn would produce plaque rupture. MMP-9 has been implicated in plaque rupture. ${ }^{57,58}$ Raposeiras-Roubín et $\mathrm{al}^{80}$ have reported that there were no significant differences in skin autofluorescence AGE and plasma sRAGE among unstable angina, STEMI and NSTEMI subjects at admission in the hospital. However, cardiac events (cardiac deaths, reinfarction, and new onset of heart failure) were associated with increased levels of sRAGE. In summary, serum levels of sRAGE were reduced in most patient but were elevated in some patients with CAD.

\section{Serum Levels of esRAGE in CAD Patients}

Wagner et $\mathrm{al}^{101}$ have reported that low plasma levels of esRAGE were associated with increased CV mortality, suggesting that esRAGE is better predictive marker than cRAGE alone. Increased levels of AGE and decreased levels of esRAGE are associated with angiographic severity and extent of CAD in patients with type 2 diabetes. ${ }^{75}$ Lu et al ${ }^{102}$ have shown that increased AGE and decreased esRAGE are associated with instent restenosis in Chinese diabetic patients. Elevated levels of serum AGE and reduced levels of serum sRAGE and esRAGE are associated with severity of albuminuria and postprocedural contrast-induced acute kidney injury, and exert a negative impact on 1-year clinical outcome in patients with type 2 diabetes undergoing PCI with Sirolimuseluting stent implantation. ${ }^{103}$ Yang et al ${ }^{104}$ have reported that lower serum levels of esRAGE were associated with higher major cardiovascular events in patients with type 2 diabetes and stable CAD undergoing PCI. Serum levels of esRAGE are lower in patients with angiographically determined coronary plaque progression in diabetic patients, ${ }^{105}$ and in subjects with greater atherosclerosis burden than control subjects. ${ }^{24,105,106}$ Serum esRAGE has been reported to be lower in patients with type 2 diabetes and CAD 
compared with control subjects, while there was no significant difference the these levels in patients with CAD in nondiabetic patients and control subjects. ${ }^{75}$ However, Colhoun et al $^{107}$ reported an elevated levels of serum esRAGE in patients with CAD. The above data suggest that the serum levels of esRAGE are reduced in patients with CAD with one exception. In summary, serum levels of esRAGE were lower in both the diabetic and nondiabetic patients with CAD.

\section{Expression of RAGE in CAD Patients}

Expression of RAGE in coronary artery of CAD patients is not available in literature. However, Rodiño-Janeiro et al ${ }^{108}$ have shown that RAGE expression in subcutaneous adipose tissue but not in epicardial adipose tissue is downregulated in patients with CAD as compared with those without CAD. RAGE expression is upregulated in atherosclerotic lesion. Expression of RAGE is elevated in carotid arterial wall of Zucker diabetic rats as compared with euglycemic control rats and the levels are further elevated in balloon-injured carotid artery of these rats. ${ }^{15}$ Arterial de-endothelialization in wild-type mice increases the expression of RAGE in injured vessels. ${ }^{16}$ Expression of RAGE in apoE $-\mid-$ mice is significantly increased in atherosclerotic plaque. ${ }^{109}$ These investigators also reported that the development of atherosclerosis was prevented in double knockout (apoE -/-/RAGE -/-) diabetic mice. In apoE $-/$ - and RAGE - /- (double knockout) mice, the plaque area is reduced. ${ }^{110}$ Forbes et al ${ }^{111}$ reported that the expression of RAGE is focally increased in atherosclerotic vascular disease. Blockade of RAGE expression with sRAGE or genetically RAGE deleted mice protected the ischemia-reperfusion myocardial injury ${ }^{112,113}$ In summary, RAGE expression was upregulated in atherosclerotic lesions in animal model of atherosclerosis and blockade of RAGE expression with sRAGE or genetically RAGE deletion $\left(\mathrm{RAGE}^{-/-}\right.$) prevented the development of atherosclerosis and ischemia reperfusion cardiac injury in mice. These data suggest that RAGE is involved in the genesis of atherosclerosis.

\section{AGE-RAGE Stress in CAD}

There are limited reports on the AGE-RAGE stress in patients with CAD. McNair et al $^{13}$ measured the ratio of AGE/sRAGE (AGE-RAGE stress) in 46 men with NSTEMI and 28 control subjects and observed that AGE/sRAGE ratio were significantly higher in patients with NSTEMI compared with control subjects. They also reported that the ratio of AGE/sRAGE was significantly elevated to a similar degree in NSTEMI with 1 vessel, 2 vessels, and 3 vessels disease when compared with control subjects. McNair et $\mathrm{al}^{14}$ investigated if post-PCI restenosis is associated with high AGE/sRAGE ratio and if pre-PCI and post-PCI levels of AGE/sRAGE were similar in patients with or without post-PCI restenosis in NSTEMI patients. They reported that pre-PCI ratio of AGE/sRAGE was greater in both groups of patients who developed or did not develop post-PCI restenosis as compared with control subjects, but the increases were more in post-PCI patients who developed restenosis than those who did not develop restenosis.
Hyperlipidemia is a risk factor for CAD. We ${ }^{114}$ investigated if hyperlipidemia is associated with increased levels of AGE/sRAGE in 100 patients with NSTEMI and observed that there was a positive correlation of AGE/sRAGE with total cholesterol, triglycerides, and LDL-C levels, and negative correlation between HDL-C and AGE/sRAGE. Kazikawa et $\mathrm{al}^{115}$ measured the endothelial cell dysfunction using flow mediated and nitroglycerine induced-vasodilation and AGE-sRAGE ratio in 110 subjects and concluded that AGE/sRAGE is an independent predictor of endothelial dysfunction. Endothelial dysfunction is precursor for atherosclerosis. The above data suggest that AGE-RAGE stress is involved in the CAD.

\section{Evidence for AGE-RAGE Stress-Induced Atherosclerosis}

Evidences suggest that AGE-RAGE stress is involved in the development of atherosclerosis. AGE and RAGE levels are elevated in carotid arterial wall of Zucker diabetic rats as compared with euglycemic control rats and the levels of AGE and RAGE are further elevated in the balloon-injured carotid artery of these rats. ${ }^{15}$ Administration of sRAGE before and for up to 21 days post-balloon injury significantly reduced neointimal hyperplasia and this was associated with decreases in vascular smooth muscle cell growth in vitro and vascular smooth muscle cell proliferation in vivo in these rats. Arterial de-endothelialization in wild-type mice increases the expression of RAGE in injured vessel, especially in smooth muscle cells, and increases deposition of AGE in expanding intima. ${ }^{16}$ They demonstrated that administration sRAGE decreased neointimal hyperplasia, smooth muscle cell proliferation and migration, and expression of extracellular matrix protein. Atherosclerosis is accelerated in streptozotocin-induced diabetes in apoE-deficient mice and this effect was associated with increased expression of VCAM-1 in aorta when compared with nondiabetic mice. ${ }^{17}$ These investigators also reported that administration of sRAGE significantly decreased the atherosclerotic lesion in a glycemicand lipid-independent manner. Expression of RAGE and VCAM-1 was elevated in aorta of apo-E deficient diabetic rats and that expression of RAGE and VCAM- 1 was downregulated with administration of sRAGE. ${ }^{116}$ sRAGE has been reported to completely suppress accelerated and advanced atherosclerosis in apoE-deficient mice. ${ }^{18}$ McNair et al $^{13}$ have reported that sRAGE levels are reduced in patients with NSTEMI. McNair et $\mathrm{l}^{14}$ have also shown that reduced serum levels of sRAGE are a predictor of restenosis following PCI. Prasad ${ }^{117}$ has discussed in detail the role of AGE and RAGE in the development and progression of carotid artery stenosis. AGE-RAGE axis may also play a role in the development of CAD. ${ }^{118}$ It is to note that ROS also depresses myocardial contractility. ${ }^{119}$ This effect of ROS would add to the cardiac effects of atherosclerosis. ROS is involved in the development of atherosclerosis. ${ }^{120-122}$

\section{Treatment Modalities for AGE-RAGE Stress- Induced CAD}

Considering the involvement of AGE-RAGE axis in genesis of atherosclerosis (CAD), the treatment target should include 
reduction in AGE, RAGE, and ROS levels, degradation of AGE in vivo, blocking of AGE-RAGE binding, and elevation of sRAGE. The treatment modalities for AGE-RAGE-induced diseases have been described in detail by Prasad and Tiwari ${ }^{123}$ and Prasad and Bhanumathy. ${ }^{54} \mathrm{~A}$ brief description of treatment of CAD is outlined below.

\section{(a) AGE-reduction}

AGE reduction in the body can be achieved by reduction in AGE intake, modification in food cooking, and other AGE lowering procedures.

1. Intake of AGE

AGE levels in the body can be lowered by reducing intake of food containing high amount of AGE (red meat, animal fat, cheese, and sweetened food). ${ }^{124}$ The use of food such as grains, legumes, breads, vegetables, fruits, and low-fat milk that contain lowest amount of AGE $^{125}$ should be encouraged.

2. Food cooking

Cooking of food at low temperature in moist heat for short duration should be advised, because it reduces the formation of AGE. ${ }^{125}$ Cooking at high temperature in dry heat (frying, broiling, grilling and roasting) increases formation of AGE. ${ }^{125}$

3. Other AGE lowering procedures

Cigarette smoking should be stopped because it increases the serum levels of AGE. ${ }^{126}$ Exercise should be advocated because exercise reduces the AGE levels. ${ }^{127,128}$ Sugar consumption should be reduced because it increases the formation of AGE. ${ }^{19,20}$

(b) Reduction in AGE formation

AGE formation can be reduced with vinegar, lemon juice, benfotiamine, pyridoxine, vitamins C, D and E, $\alpha$-lipoic acid, resveratrol, and curcumin. ${ }^{54,123}$

(c) Suppression of RAGE expression

RAGE expression is suppressed with the use of statins, candesartan, nifedipine, and rosiglitazone. ${ }^{54,117}$

(d) RAGE receptor blocker

Azeliragon has been used for AGE receptor blocker in patients with Alzheimer's disease. ${ }^{129}$ It has not been tried in other diseases.

(e) Elevation of sRAGE

sRAGE levels can be increased by upregulating the expression of SRAGE and by exogenous administration. Expression of sRAGE can be upregulated with statins, ${ }^{130}$ angiotensin converting enzyme inhibitors, ${ }^{131}$ and rosiglitazone. ${ }^{132}$ Exogenous administration of sRAGE has been successful in animal model of atherosclerosis. ${ }^{16,17,110,111}$ It has not been tried in humans.

(f) AGE degrader in vivo

Glyoxalase- 1 an endogenous enzymatic degrader of AGE has been described in detail by Prasad and Bhanumathy. ${ }^{54}$ It has not available for use. However, it has been reported that the combined use of transresveratrol found in grapes and hesperidin found in orange increases the activity of glyoxalase- 1 in placebo-control crossover clinical trial. ${ }^{133}$ Considering this, grapes and oranges might be helpful in patients with CAD. AGE receptor- mediated degrader of AGE (AGE receptor 1 [AGER1]) is not available in the market. It may serve as a future target for treatment of CAD.

(g) Antioxidants

Since ROS is generated with interaction of AGE and RAGE and ROS has been implicated in the development of atherosclerosis, ${ }^{120-122}$ antioxidants may be helpful in AGE-RAGE stress-induced atherosclerosis and CAD. Antioxidant treatment in AGE-RAGE-induced atherosclerosis has been described in detail by Prasad and Bhanumathy. ${ }^{54}$

\section{Perspectives}

CAD is due to coronary artery atherosclerosis and atherosclerotic plaque rupture resulting in coronary occlusion. AGE-RAGE axis plays a role in the development of atherosclerosis in numerous ways including reduction in the levels of NO that is known to protect atherosclerosis through vasodilation, and inhibits inflammatory mediators, platelet aggregation, and platelet activation, ${ }^{134,135}$ enhancement of atherogenic activity of LDL, ${ }^{26}$ decreasing the reverse cholesterol transport, ${ }^{136}$ and production of ROS, NF-kB, cytokines, adhesion molecules, MCP-1, GM-CSF, and growth factors described in detail in the earlier section of this chapter.

AGE, RAGE, and sRAGE may play a role in the development of atherosclerosis ${ }^{9,54}$ and plaque rupture ${ }^{55,56,58-64}$ AGE levels in serum ${ }^{66-76}$ and skin autofluorescence ${ }^{77-80}$ in patients with CAD and expression of RAGE ${ }^{15,108-113}$ in animal model of atherosclerosis are elevated, while serum esRAGE levels are reduced in patients with CAD. The serum levels of sRAGE in CAD patients are contradictory. The levels of SRAGE in patients with CAD have been reported to be reduced ${ }^{84-91}$ in some and elevated ${ }^{92-96}$ in others. The elevation of sRAGE could be due to patient selection. It is known that serum SRAGE are elevated in patients with diabetes $1^{136}$ and diabetes $2,{ }^{137}$ and in patients with impaired renal disease especially with end-stage renal disease. ${ }^{138,139}$

SRAGE is antiatherogenic because it competes with RAGE for binding with AGE. It is known that atherosclerosis develops in diabetic patients in spite of high levels of sRAGE. ${ }^{23,140}$ One would have expected that high levels of SRAGE would have protected the development of atherosclerosis in diabetic patients but it did not do so. The reason could be that elevation of AGE levels is greater than the elevation of sRAGE in diabetic patients. Hence, measurement of AGE and sRAGE in the same patient would be useful. This will allow to assess the AGE-RAGE stress that is ratio of AGE/sRAGE. ${ }^{25}$ AGE-RAGE stress is a risk factor for disease and high AGE-RAGE stress indicates the presence and severity of the disease. AGE-RAGE axis comprises of four measurable components, AGE, RAGE, sRAGE, and esRAGE. Hence, measurement of only one of these parameters would not give a true biomarker/risk marker. RAGE measurement requires tissue that is not practical in patients. Simultaneous measurements of AGE and sRAGE should be performed to assess the AGE-RAGE stress (AGE/sRAGE). Very few investigations have been performed using AGE-RAGE stress to determine biomarker/risk marker for CAD. ${ }^{13,14,114,115}$ It has been reported that $A G E / S R A G E$ are elevated in patients 
irrespective of low serum sRAGE in NSTEMI, ${ }^{13}$ thoracic aortic aneurysm, ${ }^{99}$ hyperthyroidism, ${ }^{141}$ hypercholesterolemic patients, ${ }^{114}$ and high serum levels of sRAGE in end-stage renal disease. ${ }^{139}$ It is stressed that AGE, RAGE, sRAGE, or esRAGE individually cannot serve as biomarker/risk marker. AGE-RAGE stress is the best biomarker/risk marker of CAD.

Considering involvement of AGE-RAGE axis in the development of CAD some of the therapeutic interventions, such as reduction in AGE levels and prevention of AGE formation are easy to follow. Suppression of RAGE expression and elevation of sRAGE needs drugs that are being used for lowering cholesterol levels, antidiabetic agents, angiotensin converting enzyme inhibitor, and calcium channel blocker. Patients with CAD are usually are on one or more of these drugs and hence get benefit. Some the drugs such as AGE degraders, sRAGE, and RAGE blocker (Azeliragon) are not available in the market for use in diseases except Alzheimer's disease.

\section{Conclusions}

CAD is caused by atherosclerosis of coronary artery and rupture of atherosclerotic plaques. AGE-RAGE stress can induce atherosclerosis through generation of numerous atherogenic factors. Serum AGE in CAD patients, expression of RAGE in atherosclerotic lesion in animals, and AGE-RAGE stress in CAD patients are elevated but serum esRAGE levels are reduced in CAD patients. sRAGE levels are elevated in some while reduced in other CAD patients. Treatment of AGE-RAGE stress-induced atherosclerosis includes reduction in AGE intake, prevention of AGE formation, degradation of AGE in vivo, suppression of RAGE expression, blockade of AGE-RAGE binding, elevation of sRAGE, and use of antioxidants. Treatment modalities could prevent, regress, and slow the progression of CAD.

\section{Disclosure \\ None.}

\section{Conflict of Interest}

None declared.

\section{References}

1 Wong ND. Epidemiological studies of CHD and the evolution of preventive cardiology. Nat Rev Cardiol 2014;11(05):276-289

2 World Health Organization. Global Health Estimates 2016: Deaths by Cause, Age, Sex, by Country and by Region, 2000-2016. Geneva, Switzerlandhttp://www.who.int/healthinfo/global_burden_disease /estimates/en/2016. Accessed November 16, 2018

3 Nowbar AN, Gitto M, Howard JP, Francis DP, Al-Lamee R. Mortality from ischemic heart disease. Circ Cardiovasc Qual Outcomes 2019;12(06):e005375

4 Peterson SPV, Scarborough P, Rayner M. 2005Coronary Heart Disease Statistics - 2005 edition, British Heart Foundation Health Promotion Research Group, Department of Public Health. University of OxfordEngland 2006

5 World Health Organization The World Health Report 2002. Reducing Risks, Promoting Healthy Life. World Health Organization Geneva2002

6 Prasad K. Reduction of serum cholesterol and hypercholesterolemic atherosclerosis in rabbits by secoisolariciresinol diglucoside isolated from flaxseed. Circulation 1999;99(10):1355-1362
7 Kannel WB, McGee DL. Diabetes and cardiovascular disease. The Framingham study. JAMA 1979;241(19):2035-2038

8 Kannel WB. Role of blood pressure in cardiovascular disease: the Framingham Study. Angiology 1975;26(1 Pt. 1):1-14

9 Prasad K. Pathophysiology of Atherosclerosis. New York: Springer-Verlag; 2000

10 Poirier P, Giles TD, Bray GA, et al;American Heart Association Obesity Committee of the Council on Nutrition, Physical Activity, and Metabolism. Obesity and cardiovascular disease: pathophysiology, evaluation, and effect of weight loss: an update of the 1997 American Heart Association Scientific Statement on Obesity and Heart Disease from the Obesity Committee of the Council on Nutrition, Physical Activity, and Metabolism. Circulation 2006;113(06):898-918

11 Glueck CJ, Shaw P, Lang JE, Tracy T, Sieve-Smith L, Wang Y. Evidence that homocysteine is an independent risk factor for atherosclerosis in hyperlipidemic patients. Am J Cardiol 1995;75 (02):132-136

12 Prasad K. C-reactive protein increases oxygen radical generation by neutrophils. J Cardiovasc Pharmacol Ther 2004;9(03): 203-209

13 McNair ED, Wells CR, Qureshi AM, et al. Low levels of soluble receptor for advanced glycation end products in non-ST elevation myocardial infarction patients. Int J Angiol 2009;18(04): 187-192

14 McNair ED, Wells CR, Mabood Qureshi A, et al. Soluble receptors for advanced glycation end products (sRAGE) as a predictor of restenosis following percutaneous coronary intervention. Clin Cardiol 2010;33(11):678-685

15 Zhou Z, Wang K, Penn MS, et al. Receptor for AGE (RAGE) mediates neointimal formation in response to arterial injury. Circulation 2003;107(17):2238-2243

16 Sakaguchi T, Yan SF, Yan SD, et al. Central role of RAGE-dependent neointimal expansion in arterial restenosis. J Clin Invest 2003;111(07):959-972

17 Wendt TM. Accelerated atherosclerosis and vascular inflammation develop in apoE null mice with type 2 diabetes. Circulation 2000;102:II-231

18 Park L, Raman KG, Lee KJ, et al. Suppression of accelerated diabetic atherosclerosis by the soluble receptor for advanced glycation endproducts. Nat Med 1998;4(09):1025-1031

19 Prasad K. Soluble receptor for advanced glycation end products (sRAGE) and cardiovascular disease. Int J Angiol 2006;15:57-68

20 Bucala R, Cerami A. Advanced glycosylation: chemistry, biology, and implications for diabetes and aging. Adv Pharmacol 1992; 23:1-34

21 Tam XH, Shiu SW, Leng L, Bucala R, Betteridge DJ, Tan KC. Enhanced expression of receptor for advanced glycation end-products is associated with low circulating soluble isoforms of the receptor in type 2 diabetes. Clin Sci (Lond) 2011;120(02):81-89

22 Yonekura H, Yamamoto Y, Sakurai S, et al. Novel splice variants of the receptor for advanced glycation end-products expressed in human vascular endothelial cells and pericytes, and their putative roles in diabetes-induced vascular injury. Biochem J 2003; 370(Pt 3):1097-1109

23 Prasad K, Dhar I, Zhou Q, Elmoselhi H, Shoker M, Shoker A. AGEs/sRAGE, a novel risk factor in the pathogenesis of end-stage renal disease. Mol Cell Biochem 2016;423(1-2):105-114

24 Koyama H, Shoji T, Yokoyama H, et al. Plasma level of endogenous secretory RAGE is associated with components of the metabolic syndrome and atherosclerosis. Arterioscler Thromb Vasc Biol 2005;25(12):2587-2593

25 Prasad K, Mishra M. AGE-RAGE stress, stressors, and antistressors in health and disease. Int J Angiol 2018;27(01):1-12

26 Bucala R, Makita Z, Vega G, et al. Modification of low density lipoprotein by advanced glycation end products contributes to the dyslipidemia of diabetes and renal insufficiency. Proc Natl Acad Sci U S A 1994;91(20):9441-9445 
27 Brownlee M, Vlassara H, Cerami A. Nonenzymatic glycosylation products on collagen covalently trap low-density lipoprotein. Diabetes 1985;34(09):938-941

28 Bucala R, Makita Z, Koschinsky T, Cerami A, Vlassara H. Lipid advanced glycosylation: pathway for lipid oxidation in vivo. Proc Natl Acad Sci U S A 1993;90(14):6434-6438

29 Horiuchi S, Sakamoto Y, Sakai M. Scavenger receptors for oxidized and glycated proteins. Amino Acids 2003;25(34):283-292

30 Haberland ME, Fless GM, Scanu AM, Fogelman AM. Malondialdehyde modification of lipoprotein(a) produces avid uptake by human monocyte-macrophages. J Biol Chem 1992;267(06): 4143-4151

31 Makita T, Tanaka A, Numano F. Effect of glycated low density lipoprotein on smooth muscle cell proliferation. Int Angiol 1999; 18(04):331-334

32 Brown BE, Dean RT, Davies MJ. Glycation of low-density lipoproteins by methylglyoxal and glycolaldehyde gives rise to the in vitro formation of lipid-laden cells. Diabetologia 2005;48(02): 361-369

33 Sutton G, Pugh D, Dhaun N. Developments in the role of endothelin-1 in atherosclerosis: a potential therapeutic target? Am J Hypertens 2019;32(09):813-815

34 Brownlee M, Cerami A, Vlassara H. Advanced glycosylation end products in tissue and the biochemical basis of diabetic complications. N Engl J Med 1988;318(20):1315-1321

35 Tanaka S, Avigad G, Brodsky B, Eikenberry EF. Glycation induces expansion of the molecular packing of collagen. J Mol Biol 1988; 203(02):495-505

36 Quehenberger P, Bierhaus A, Fasching P, et al. Endothelin 1 transcription is controlled by nuclear factor-kappaB in AGEstimulated cultured endothelial cells. Diabetes 2000;49(09): $1561-1570$

37 Chakravarthy U, Hayes RG, Stitt AW, McAuley E, Archer DB. Constitutive nitric oxide synthase expression in retinal vascular endothelial cells is suppressed by high glucose and advanced glycation end products. Diabetes 1998;47(06):945-952

38 Ren X, Ren L, Wei Q, Shao H, Chen L, Liu N. Advanced glycation end-products decreases expression of endothelial nitric oxide synthase through oxidative stress in human coronary artery endothelial cells. Cardiovasc Diabetol 2017;16(01):52

39 Bucala R, Tracey KJ, Cerami A. Advanced glycosylation products quench nitric oxide and mediate defective endothelium-dependent vasodilatation in experimental diabetes. J Clin Invest 1991; 87(02):432-438

40 Goldin A, Beckman JA, Schmidt AM, Creager MA. Advanced glycation end products: sparking the development of diabetic vascular injury. Circulation 2006;114(06):597-605

41 Hogan M, Cerami A, Bucala R. Advanced glycosylation endproducts block the antiproliferative effect of nitric oxide. Role in the vascular and renal complications of diabetes mellitus. J Clin Invest 1992;90(03):1110-1115

42 Wautier MP, Chappey O, Corda S, Stern DM, Schmidt AM, Wautier JL. Activation of NADPH oxidase by AGE links oxidant stress to altered gene expression via RAGE. Am J Physiol Endocrinol Metab 2001;280(05):E685-E694

43 Reznikov LL, Waksman J, Azam T, et al. Effect of advanced glycation end products on endotoxin-induced TNF-alpha, IL1 beta and IL- 8 in human peripheral blood mononuclear cells. Clin Nephrol 2004;61(05):324-336

44 Stassen M, Müller C, Arnold M, et al. IL-9 and IL-13 production by activated mast cells is strongly enhanced in the presence of lipopolysaccharide: NF-kappa B is decisively involved in the expression of IL-9. J Immunol 2001;166(07):4391-4398

45 Basta G, Lazzerini G, Massaro M, et al. Advanced glycation end products activate endothelium through signal-transduction receptor RAGE: a mechanism for amplification of inflammatory responses. Circulation 2002;105(07):816-822
46 Chiu JJ, Wung BS, Shyy JY, Hsieh HJ, Wang DL. Reactive oxygen species are involved in shear stress-induced intercellular adhesion molecule-1 expression in endothelial cells. Arterioscler Thromb Vasc Biol 1997;17(12):3570-3577

47 Fraticelli A, Serrano CV Jr, Bochner BS, Capogrossi MC, Zweier JL. Hydrogen peroxide and superoxide modulate leukocyte adhesion molecule expression and leukocyte endothelial adhesion. Biochim Biophys Acta 1996;1310(03):251-259

48 Willam C, Schindler R, Frei U, Eckardt KU. Increases in oxygen tension stimulate expression of ICAM- 1 and VCAM- 1 on human endothelial cells. Am J Physiol 1999;276(06):H2044-H2052

49 Matsui T, Yamagishi S, Ueda S, et al. Telmisartan, an angiotensin II type 1 receptor blocker, inhibits advanced glycation endproduct (AGE)-induced monocyte chemoattractant protein-1 expression in mesangial cells through downregulation of receptor for AGEs via peroxisome proliferator-activated receptorgamma activation. J Int Med Res 2007;35(04):482-489

50 Yamagishi S, Inagaki Y, Okamoto T, et al. Advanced glycation end product-induced apoptosis and overexpression of vascular endothelial growth factor and monocyte chemoattractant protein1 in human-cultured mesangial cells. J Biol Chem 2002;277(23): 20309-20315

51 Sasaki T, Horiuchi S, Yamazaki M, Yui S. Induction of GM-CSF production of macrophages by advanced glycation end products of the Maillard reaction. Biosci Biotechnol Biochem 1999;63 (11):2011-2013

52 Kirstein M, Aston C, Hintz R, Vlassara H. Receptor-specific induction of insulin-like growth factor I in human monocytes by advanced glycosylation end product-modified proteins. J Clin Invest 1992;90(02):439-446

53 Wolf YG, Rasmussen LM, Ruoslahti E. Antibodies against transforming growth factor-beta 1 suppress intimal hyperplasia in a rat model. J Clin Invest 1994;93(03):1172-1178

54 Prasad K, Bhanumathy KK. AGE-RAGE axis in the pathophysiology of chronic lower limb ischemia and a novel strategy for its treatment. Int J Angiol 2020;29(03):156-167

55 Braunwald E, Jones RH, Mark DB, et al;Agency for Health Care Policy and Research. Diagnosing and managing unstable angina. Circulation 1994;90(01):613-622

56 Fuster V, Gotto AM, Libby P, Loscalzo J, McGill HC. 27th Bethesda Conference: matching the intensity of risk factor management with the hazard for coronary disease events. Task Force 1. Pathogenesis of coronary disease: the biologic role of risk factors. J Am Coll Cardiol 1996;27(05):964-976

57 Nikkari ST, O'Brien KD, Ferguson M, et al. Interstitial collagenase (MMP-1) expression in human carotid atherosclerosis. Circulation 1995;92(06):1393-1398

58 Brown DL, Hibbs MS, Kearney M, Loushin C, Isner JM. Identification of $92-k D$ gelatinase in human coronary atherosclerotic lesions. Association of active enzyme synthesis with unstable angina. Circulation 1995;91(08):2125-2131

59 Brown RD, Jones GM, Laird RE, Hudson P, Long CS. Cytokines regulate matrix metalloproteinases and migration in cardiac fibroblasts. Biochem Biophys Res Commun 2007;362(01): 200-205

60 Osawa H, Yamabe H, Kaizuka M, et al. Platelet-derived growth factor stimulates matrix metalloproteinase-2 secretion in cultured human mesangial cells. Clin Exp Nephrol 2002;6(04): 202-206

61 Sasaki M, Kashima M, Ito T, et al. Differential regulation of metalloproteinase production, proliferation and chemotaxis of human lung fibroblasts by PDGF, interleukin-1 beta and TNFalpha. Mediators Inflamm 2000;9(3-4):155-160

62 Alge-Priglinger CS, Kreutzer T, Obholzer K, et al. Oxidative stressmediated induction of MMP-1 and MMP-3 in human RPE cells. Invest Ophthalmol Vis Sci 2009;50(11):5495-5503

63 Spallarossa P, Altieri P, Garibaldi S, et al. Matrix metalloproteinase-2 and -9 are induced differently by doxorubicin in H9c2 
cells: The role of MAP kinases and NAD(P)H oxidase. Cardiovasc Res 2006;69(03):736-745

64 Channon KM. Oxidative stress and coronary plaque stability. Arterioscler Thromb Vasc Biol 2002;22(11):1751-1752

65 Da Moura Semedo C, Webb M, Waller H, Khunti K, Davies M. Skin autofluorescence, a non-invasive marker of advanced glycation end products: clinical relevance and limitations. Postgrad Med J 2017;93(1099):289-294

66 Kilhovd BK, Berg TJ, Birkeland KI, Thorsby P, Hanssen KF. Serum levels of advanced glycation end products are increased in patients with type 2 diabetes and coronary heart disease. Diabetes Care 1999;22(09):1543-1548

67 Kilhovd BK, Juutilainen A, Lehto S, et al. Increased serum levels of advanced glycation endproducts predict total, cardiovascular and coronary mortality in women with type 2 diabetes: a population-based 18 year follow-up study. Diabetologia 2007; 50(07):1409-1417

68 Kanauchi M, Tsujimoto N, Hashimoto T. Advanced glycation end products in nondiabetic patients with coronary artery disease. Diabetes Care 2001;24(09):1620-1623

69 Choi EY, Kwon HM, Ahn CW, et al. Serum levels of advanced glycation end products are associated with in-stent restenosis in diabetic patients. Yonsei Med J 2005;46(01):78-85

70 Kiuchi K, Nejima J, Takano T, Ohta M, Hashimoto H. Increased serum concentrations of advanced glycation end products: a marker of coronary artery disease activity in type 2 diabetic patients. Heart 2001;85(01):87-91

71 Yeboah FK, Alli I, Yaylayan VA, Yasuo K, Chowdhury SF, Purisima EO. Effect of limited solid-state glycation on the conformation of lysozyme by ESI-MSMS peptide mapping and molecular modeling. Bioconjug Chem 2004;15(01):27-34

72 Kerkeni M, Weiss IS, Jaisson S, et al. Increased serum concentrations of pentosidine are related to presence and severity of coronary artery disease. Thromb Res 2014;134(03):633-638

73 van Eupen MG, Schram MT, Colhoun HM, Scheijen JL, Stehouwer CD, Schalkwijk CG. Plasma levels of advanced glycation endproducts are associated with type 1 diabetes and coronary artery calcification. Cardiovasc Diabetol 2013;12:149

74 Semba RD, Bandinelli S, Sun K, Guralnik JM, Ferrucci L. Plasma carboxymethyl-lysine, an advanced glycation end product, and all-cause and cardiovascular disease mortality in older community-dwelling adults. J Am Geriatr Soc 2009;57(10):1874-1880

$75 \mathrm{Lu} \mathrm{L}, \mathrm{Pu}$ LJ, Zhang Q et al. Increased glycated albumin and decreased esRAGE levels are related to angiographic severity and extent of coronary artery disease in patients with type 2 diabetes. Atherosclerosis 2009;206(02):540-545

76 Aso Y, Inukai T, Tayama K, Takemura Y. Serum concentrations of advanced glycation endproducts are associated with the development of atherosclerosis as well as diabetic microangiopathy in patients with type 2 diabetes. Acta Diabetol 2000;37(02):87-92

77 Mulder DJ, van Haelst PL, Gross S, et al. Skin autofluorescence is elevated in patients with stable coronary artery disease and is associated with serum levels of neopterin and the soluble receptor for advanced glycation end products. Atherosclerosis 2008;197(01):217-223

78 Yozgatli K, Lefrandt JD, Noordzij MJ, et al. Accumulation of advanced glycation end products is associated with macrovascular events and glycaemic control with microvascular complications in type 2 diabetes mellitus. Diabet Med 2018

79 Conway B, Edmundowicz D, Matter N, Maynard J, Orchard T. Skin fluorescence correlates strongly with coronary artery calcification severity in type 1 diabetes. Diabetes Technol Ther 2010;12 (05):339-345

80 Raposeiras-Roubín S, Rodiño-Janeiro BK, Paradela-Dobarro B, et al. Fluorescent advanced glycation end products and their soluble receptor: the birth of new plasmatic biomarkers for risk stratification of acute coronary syndrome. PLoS One 2013;8(09): e74302
81 Hartog JW, Voors AA, Bakker SJ, Smit AJ, van Veldhuisen DJ. Advanced glycation end-products (AGEs) and heart failure: pathophysiology and clinical implications. Eur J Heart Fail 2007;9(12):1146-1155

82 Bidasee KR, Nallani K, Yu Y, et al. Chronic diabetes increases advanced glycation end products on cardiac ryanodine receptors/calcium-release channels. Diabetes 2003;52(07):1825-1836

83 Selvin E, Halushka MK, Rawlings AM, et al. sRAGE and risk of diabetes, cardiovascular disease, and death. Diabetes 2013;62 (06):2116-2121

84 Falcone C, Emanuele E, D'Angelo A, et al. Plasma levels of soluble receptor for advanced glycation end products and coronary artery disease in nondiabetic men. Arterioscler Thromb Vasc Biol 2005;25(05):1032-1037

85 Falcone C, Bozzini S, D’Angelo A, et al. Plasma levels of soluble receptor for advanced glycation end products and coronary atherosclerosis: possible correlation with clinical presentation. Dis Markers 2013;35(03):135-140

86 Mahajan N, Malik N, Bahl A, Dhawan V. Receptor for advanced glycation end products (RAGE) and its inflammatory ligand ENRAGE in non-diabetic subjects with pre-mature coronary artery disease. Atherosclerosis 2009;207(02):597-602

87 Danzig V, Míková B, Kuchynka P, et al. Levels of circulating biomarkers at rest and after exercise in coronary artery disease patients. Physiol Res 2010;59(03):385-392

88 Falcone C, Bozzini S, Guasti L, et al. Soluble RAGE plasma levels in patients with coronary artery disease and peripheral artery disease. ScientificWorldJournal 2013;2013:584504

89 Chiang KH, Huang PH, Huang SS, Wu TC, Chen JW, Lin SJ. Plasma levels of soluble receptor for advanced glycation end products are associated with endothelial function and predict cardiovascular events in nondiabetic patients. Coron Artery Dis 2009;20 (04):267-273

90 Lindsey JB, de Lemos JA, Cipollone F, et al. Association between circulating soluble receptor for advanced glycation end products and atherosclerosis: observations from the Dallas Heart Study. Diabetes Care 2009;32(07):1218-1220

91 McNair ED, Wells CR, Qureshi AM, Pearce C, Caspar-Bell G, Prasad K. Inverse Association between cardiac troponin-I and soluble receptor for advanced glycation end products in patients with non-ST-segment elevation myocardial infarction. Int J Angiol 2011;20(01):49-54

92 Basta G, Del Turco S, Marchi F, et al. Elevated soluble receptor for advanced glycation end product levels in patients with acute coronary syndrome and positive cardiac troponin I. Coron Artery Dis 2011;22(08):590-594

93 Nakamura K, Yamagishi S, Adachi H, et al. Elevation of soluble form of receptor for advanced glycation end products (sRAGE) in diabetic subjects with coronary artery disease. Diabetes Metab Res Rev 2007;23(05):368-371

94 Cai XY, Lu L, Wang YN, et al. Association of increased S100B, S100A6 and S100P in serum levels with acute coronary syndrome and also with the severity of myocardial infarction in cardiac tissue of rat models with ischemia-reperfusion injury. Atherosclerosis 2011;217(02):536-542

95 Jensen LJ, Flyvbjerg A, Bjerre M. Soluble receptor for advanced glycation end product: a biomarker for acute coronary syndrome. BioMed Res Int 2015;2015:815942

96 Park HJ, Baek JY, Shin WS, et al. Soluble receptor of advanced glycated endproducts is associated with plaque vulnerability in patients with acute myocardial infarction. Circ J 2011;75(07): $1685-1690$

97 Wang X, Xu T, Mungun D, et al. The relationship between plasma soluble receptor for advanced glycation end products and coronary artery disease. Dis Markers 2019;2019:4528382

98 Prasad K. Is there any evidence that AGE/sRAGE is a universal biomarker/risk marker for diseases? Mol Cell Biochem 2019;451 (1-2):139-144 
99 Prasad K, Sarkar A, Zafar MA, et al. Advanced glycation end products and its soluble receptors in the pathogenesis of thoracic aortic aneurysm. Aorta (Stamford) 2016;4(01):1-10

100 Zhang F, Kent KC, Yamanouchi D, et al. Anti-receptor for advanced glycation end products therapies as novel treatment for abdominal aortic aneurysm. Ann Surg 2009;250(03):416-423

101 Wagner Z, Molnár M, Molnár GA, et al. Serum carboxymethyllysine predicts mortality in hemodialysis patients. Am J Kidney Dis 2006;47(02):294-300

102 Lu L, Jin Pu L, Chen QJ, et al. Increased glycated albumin and decreased esRAGE concentrations are associated with in-stent restenosis in Chinese diabetic patients. Clin Chim Acta 2008;396 (1-2):33-37

103 Shen Y, Pu LJ, Lu L, Zhang Q, Zhang RY, Shen WF. Serum advanced glycation end-products and receptors as prognostic biomarkers in diabetics undergoing coronary artery stent implantation. Can J Cardiol 2012;28(06):737-743

104 Yang ZK, Shen Y, Shen WF, et al. Elevated glycated albumin and reduced endogenous secretory receptor for advanced glycation endproducts levels in serum predict major adverse cardio-cerebral events in patients with type 2 diabetes and stable coronary artery disease. Int J Cardiol 2015;197:241-247

105 Peng WH, Lu L, Hu J, et al. Decreased serum esRAGE level is associated with angiographically determined coronary plaque progression in diabetic patients. Clin Biochem 2009;42(12): 1252-1259

106 Katakami N, Matsuhisa M, Kaneto H, Yamasaki Y. Serum endogenous secretory RAGE levels are inversely associated with carotid IMT in type 2 diabetic patients. Atherosclerosis 2007;190(01): $22-23$

107 Colhoun HM, Betteridge DJ, Durrington P, et al. Total soluble and endogenous secretory receptor for advanced glycation end products as predictive biomarkers of coronary heart disease risk in patients with type 2 diabetes: an analysis from the CARDS trial. Diabetes 2011;60(09):2379-2385

108 Rodiño-Janeiro BK, Salgado-Somoza A, Teijeira-Fernández E, González-Juanatey JR, Alvarez E, Eiras S. Receptor for advanced glycation end-products expression in subcutaneous adipose tissue is related to coronary artery disease. Eur J Endocrinol 2011;164(04):529-537

109 Soro-Paavonen A, Watson AM, Li J, et al. Receptor for advanced glycation end products (RAGE) deficiency attenuates the development of atherosclerosis in diabetes. Diabetes 2008;57(09): 2461-2469

110 Harja E, Bu DX, Hudson BI, et al. Vascular and inflammatory stresses mediate atherosclerosis via RAGE and its ligands in apoE-/- mice. J Clin Invest 2008;118(01):183-194

111 Forbes JM, Yee LT, Thallas V, et al. Advanced glycation end product interventions reduce diabetes-accelerated atherosclerosis. Diabetes 2004;53(07):1813-1823

112 Aleshin A, Ananthakrishnan R, Li Q et al. RAGE modulates myocardial injury consequent to LAD infarction via impact on JNK and STAT signaling in a murine model. Am J Physiol Heart Circ Physiol 2008;294(04):H1823-H1832

113 Bucciarelli LG, Kaneko M, Ananthakrishnan R, et al. Receptor for advanced-glycation end products: key modulator of myocardial ischemic injury. Circulation 2006;113(09):1226-1234

114 McNair E, Qureshi M, Prasad K, Pearce C. Atherosclerosis and the hypercholesterolemic AGE-RAGE axis. Int J Angiol 2016;25(02): 110-116

115 Kajikawa M, Nakashima A, Fujimura N, et al. Ratio of serum levels of AGEs to soluble form of RAGE is a predictor of endothelial function. Diabetes Care 2015;38(01):119-125

116 Kislinger T, Tanji N, Wendt T, et al. Receptor for advanced glycation end products mediates inflammation and enhanced expression of tissue factor in vasculature of diabetic apolipoprotein E-null mice. Arterioscler Thromb Vasc Biol 2001;21(06): 905-910
117 Prasad K. Pathophysiology and medical treatment of carotid artery stenosis. Int J Angiol 2015;24(03):158-172

118 Fishman SL, Sonmez H, Basman C, Singh V, Poretsky L. The role of advanced glycation end-products in the development of coronary artery disease in patients with and without diabetes mellitus: a review. Mol Med 2018;24(01):59

119 Prasad K, Kalra J, Bharadwaj L. Cardiac depressant effects of oxygen free radicals. Angiology 1993;44(04):257-270

120 Kattoor AJ, Pothineni NVK, Palagiri D, Mehta JL. Oxidative stress in atherosclerosis. Curr Atheroscler Rep 2017;19(11):42

121 Prasad K, Kalra J. Oxygen free radicals and hypercholesterolemic atherosclerosis: effect of vitamin E. Am Heart J 1993;125(04): 958-973

122 Yang X, Li Y, Li Y, et al. Oxidative stress-mediated atherosclerosis: mechanisms and therapies. Front Physiol 2017;8:600

123 Prasad K, Tiwari S. Therapeutic interventions for advanced glycation-end products and its receptor- mediated cardiovascular disease. Curr Pharm Des 2017;23(06):937-943

124 Weisenberger J. Foods High in AGEs. http://wwwdiabetesforecastorg/2014/11-nov/foods-high-in-ages.html. Accessed Nov 15, 2020

125 Uribarri J, Woodruff S, Goodman S, et al. Advanced glycation end products in foods and a practical guide to their reduction in the diet. J Am Diet Assoc 2010;110(06):911-16.e12

126 Prasad K, Dhar I, Caspar-Bell G. Role of advanced glycation end products and its receptors in the pathogenesis of cigarette smoke-induced cardiovascular disease. Int J Angiol 2015;24 (02):75-80

127 Kondoh Y, Kawase M, Ohmori S. D-lactate concentrations in blood, urine and sweat before and after exercise. Eur J Appl Physiol Occup Physiol 1992;65(01):88-93

128 Salama ME, Eldamarawi M, Salama AF. A comparison between the impact of two different exercise protocols on advanced glycation end products in type 2 diabetic rats. Life Sci J 2013; 10:860-869

129 Burstein AH, Sabbagh M, Andrews R, Valcarce C, Dunn I, Altstiel L. Development of Azeliragon, an oral small molecule antagonist of the receptor for advanced glycation endproducts, for the potential slowing of loss of cognition in mild Alzheimer's disease. J Prev Alzheimers Dis 2018;5(02):149-154

130 Tam HL, Shiu SW, Wong Y, Chow WS, Betteridge DJ, Tan KC. Effects of atorvastatin on serum soluble receptors for advanced glycation end-products in type 2 diabetes. Atherosclerosis 2010; 209(01):173-177

131 Forbes JM, Thorpe SR, Thallas-Bonke V, et al. Modulation of soluble receptor for advanced glycation end products by angiotensin-converting enzyme-1 inhibition in diabetic nephropathy. J Am Soc Nephrol 2005;16(08):2363-2372

132 Tan KCB, Chow WS, Tso AWK, et al. Thiazolidinedione increases serum soluble receptor for advanced glycation end-products in type 2 diabetes. Diabetologia 2007;50(09):1819-1825

133 Xue M, Weickert MO, Qureshi S, et al. Improved glycemic control and vascular function in overweight and obese subjects by glyoxalase 1 inducer formulation. Diabetes 2016;65(08): 2282-2294

134 Harrison DG. Cellular and molecular mechanisms of endothelial cell dysfunction. J Clin Invest 1997;100(09):2153-2157

135 Persson F, Rossing P, Hovind P, et al. Endothelial dysfunction and inflammation predict development of diabetic nephropathy in the irbesartan in patients with type 2 diabetes and microalbuminuria (IRMA 2) study. Scand J Clin Lab Invest 2008;68(08): 731-738

136 Khera AV, Cuchel M, de la Llera-Moya M, et al. Cholesterol efflux capacity, high-density lipoprotein function, and atherosclerosis. N Engl J Med 2011;364(02):127-135

137 Nin JW, Jorsal A, Ferreira I, et al. Higher plasma soluble receptor for advanced glycation end products (sRAGE) levels are associated with incident cardiovascular disease and all-cause 
14 AGE-RAGE Stress and CAD Prasad et al.

mortality in type 1 diabetes: a 12-year follow-up study. Diabetes 2010;59(08):2027-2032

138 Fujisawa K, Katakami N, Kaneto H, et al. Circulating soluble RAGE as a predictive biomarker of cardiovascular event risk in patients with type 2 diabetes. Atherosclerosis 2013;227(02): 425-428

139 Kalousová M, Hodková M, Kazderová M, et al. Soluble receptor for advanced glycation end products in patients with decreased renal function. Am J Kidney Dis 2006;47(03):406-411
140 Tan KC, Shiu SW, Chow WS, Leng L, Bucala R, Betteridge DJ. Association between serum levels of soluble receptor for advanced glycation end products and circulating advanced glycation end products in type 2 diabetes. Diabetologia 2006;49(11): 2756-2762

141 Challier M, Jacqueminet S, Benabdesselam O, Grimaldi A, Beaudeux JL. Increased serum concentrations of soluble receptor for advanced glycation endproducts in patients with type 1 diabetes. Clin Chem 2005;51(09):1749-1750 